\section{THE SALE OF TARANTULAS IN CAMBODIA FOR FOOD OR MEDICINE: IS IT SUSTAINABLE?}

\section{Alan L Yen ${ }^{1} \&$ Sophoanrith Ro ${ }^{2}$}

${ }^{1}$ Biosciences Research Division, Department of Primary Industries, 621 Burwood Highway, Knoxfield, Victoria, Australia 3156

${ }^{2}$ Faculty of Agronomy, Royal University of Agriculture, Chamkar Daung, Daungkor District, P.O. Box 2696, Phnom Penh, Cambodia

${ }^{1}$ alan.yen@dpi.vic.gov.au (corresponding author), ${ }^{2}$ sophoanrith@yahoo.com

There is little information about the use of spiders in medicine or as a food source for people. Spiders were used for medicinal purposes in China (Read 1941) and Mexico (Machkour-M'Rabet et al. 2011). Spiders have been reported as food in Cambodia and Thailand (Bristowe 1932), Papua New Guinea (Robinson \& Robinson 1976), northeastern India (Meyer-Rochow \& Changkija 1997), and Venezuela (Paoletti \& Dufour 2005).

With increasing foreign tourism to Cambodia over recent years, there are many internet references to the fried tarantulas sold as food. They are called 'a-ping' by Cambodians, but the species identity of the spiders sold is uncertain. The main outlet for these tarantulas is the small town of Skun (also spelt Skuon) located in Kompong Cham Province about $90 \mathrm{~km}$ north of Phnom Penh. Skun is known as "spider town" to many Cambodians.

Anecdotal information suggests that these tarantulas were used locally for medicinal purposes in the past (Rigby 2002). Some Cambodians believe that the tarantulas are nutritious, good for the heart, throat and lungs, cure back aches and breathing problems, have aphrodisiac properties, and make women more beautiful (Rigby 2002; Byrne 2009; DuFord 2009; Midena 2010; Serath 2011). Many people believe that male spiders mixed with rice wine also relieve pain and treat asthma and other respiratory complaints (Serath 2011). One trader stated that it is important that spiders in rice wine still have their fangs or else the medicine loses its effectiveness (CamboGuide

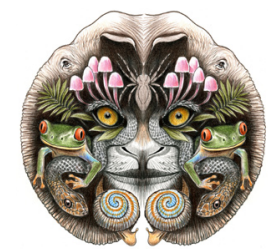

ISSN

Online 0974-7907 Print 0974-7893

\section{OPEN ACCESS} undated). They apparently became a dietary item as a result of starvation during the Pol Pot regime (Rigby 2002; Byrne 2009; DuFord 2009), although some vendors claim that Cambodians have been eating them for a long time (Serath 2011).

The spiders are sold either cooked or live. Cooked spiders are washed, fried with salt, sugar and condiments (Serath 2011) and then dipped into garlic or monosodium glutamate (Fuller-Love 2011; Wijesinghe undated). Only female spiders, which are larger than the males, are cooked as food (Serath 2011). Some are sold in larger towns, and live spiders can also be purchased at the Central, Orussey and Psar Chas markets in Phnom Penh (Serath 2011). The volume of trade is unknown; Serath (2011) indicates that 500-1,000 spiders are sold each day but does not indicate how many vendors are involved.

A-ping lives underground in tropical forests. A good spider collector is able to dig up several hundred spiders each day (Rigby 2002). A-ping are generally available throughout the year (Serath 2011). There are claims that the spiders are bred (Midena 2010) but there is no evidence that this occurs. Spiders are collected locally around Skun, but there are reports of a decline in the local spider populations and supplies are obtained from other nearby provinces. Some sellers blame the destruction of the rainforests and other agriculture ventures for the decline in spider numbers, although

DOI: http://dx.doi.org/10.11609/JoTT.03149.153 | ZooBank: urn:Isid:zoobank.org:pub:74DB51AE-2B99-4C6E-828F-1C58B76E183B

Manuscript details: Ms \# o3149 | Received 03 April 2012 | Final received 31 August 2012 | Finally accepted 07 November 2012

Citation: Yen, A.L. \& S. Ro (2013). The sale of tarantulas in Cambodia for food or medicine: is it sustainable?. Journal of Threatened Taxa 5(1): 3548-3551; doi:10.11609/JoTT.03149.153

Copyright: @ Yen \& Ro 2013. Creative Commons Attribution 3.0 Unported License. JoTT allows unrestricted use of this article in any medium, reproduction and distribution by providing adequate credit to the authors and the source of publication.

Funding: This was funded by the Department of Primary Industries Victoria and an Australian Government Endeavour Executive Award.

Competing Interest: None.

Acknowledgements: Alan Yen acknowledges the assistance of an Australian Government Endeavour Executive Award to study edible insects in Southeast Asia. The authors wish to thank Nanna Roos, University of Copenhagen, for information on the nutritional value of the tarantulas, and Sorn Norng, Department of Primary Industries Victoria, for valuable comments on the manuscript. 
other collectors claim they collect them from cashew nut plantations that have replaced some of the forests (Byrne 2009; Midena 2010). Serath (2011) reported that they are supplied daily to Skun from collectors who live in Siem Reap and Kompong Thom provinces (Serath 2011).

In a poor nation still recovering from the hardships of the Pol Pot regime, income derived from selling spiders can be substantial. Rigby (2002) cited a vendor who sold 100-200 spiders a day; they were purchased for 150 Cambodian Riel each and sold for 300 Riel, so the vendor could derive a daily income of 15,000-30,000 Riel (US\$1.00 = approximately 4,000 Riel). Serath (2011) reported that a single female a-ping sells for $600-800$ Riel. What is the effect of this high extraction rate of tarantulas as food? This is not known. The large number of specimens that a single vendor has for sale suggests that this resource may not be sustainable (Byrne 2009; Garcia 2012; Phnom Penh Post 2012).

The authors visited Skun on 11 September 2011 and the following information was obtained by questioning several of the spider vendors and by observations. There are several roadside stops, one of which is a bus terminus. Food, including the spiders, is sold at all these stops. One of the stops has large sculptures of the spiders (Image 1). Both cooked (Image 2) and live spiders (Image 3) were sold at the Skun outlets. The individual vendors were scattered over several stops; there were 10 vendors selling spiders at the main bus terminal on the day of our visit. Many of the vendors had stalls that sell a variety of other types of foods besides insects and spiders. According to one vendor, there are about 30 vendors operating around Skun who sell spiders.

When asked what they knew about the biology of the spiders, we were informed that they lay their eggs in December and that they moult around September, but it was difficult to get elaboration on these observations in the time available. We were told that some spiders are sold when they are about seven months old, but the live ones are generally about 1.5 years old when they are sold. Care must be taken when considering this information because the vendors purchase the spiders a few days before they sell them and their estimates are probably not based upon personal observations or credible scientific measurement.

Some of the spiders are collected locally, but they are now difficult to find because, according to vendors, the forests have been cleared. The spiders are now collected from forests in Preah Vihear Province (near the Thai border) and in the Sandan District of Kompong Thom Province.

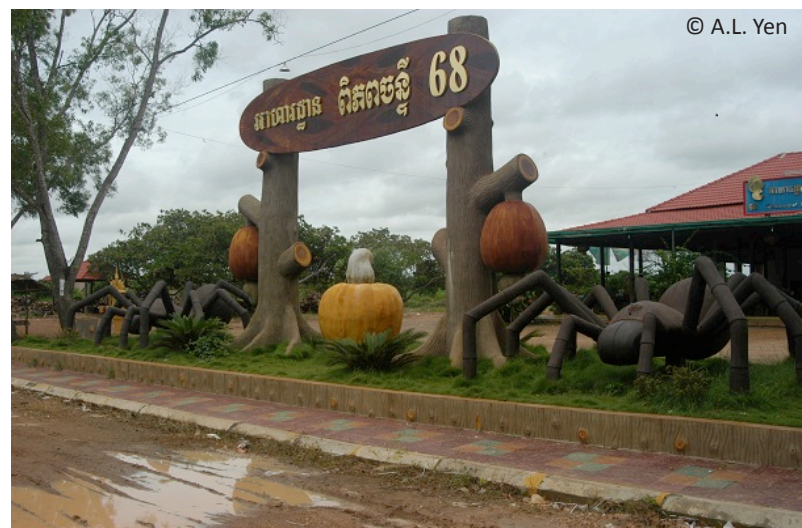

Image 1. Spiderville statues at Skun

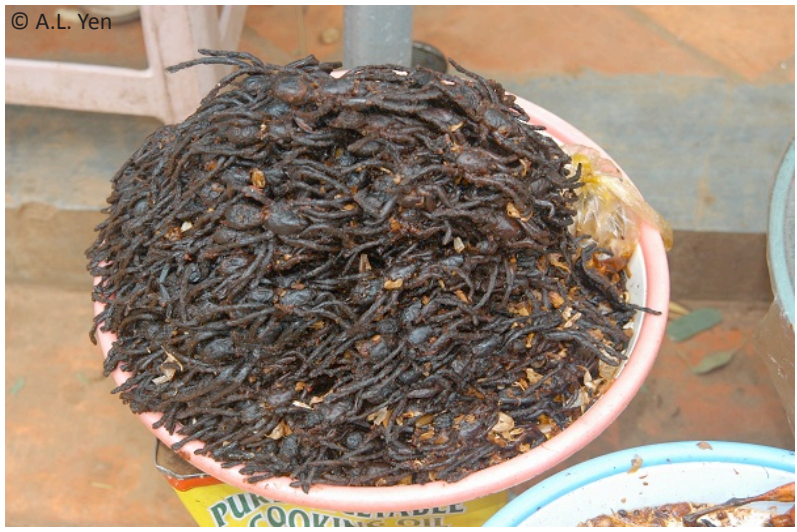

Image 2. Deep fried tarantulas for sale at Skun

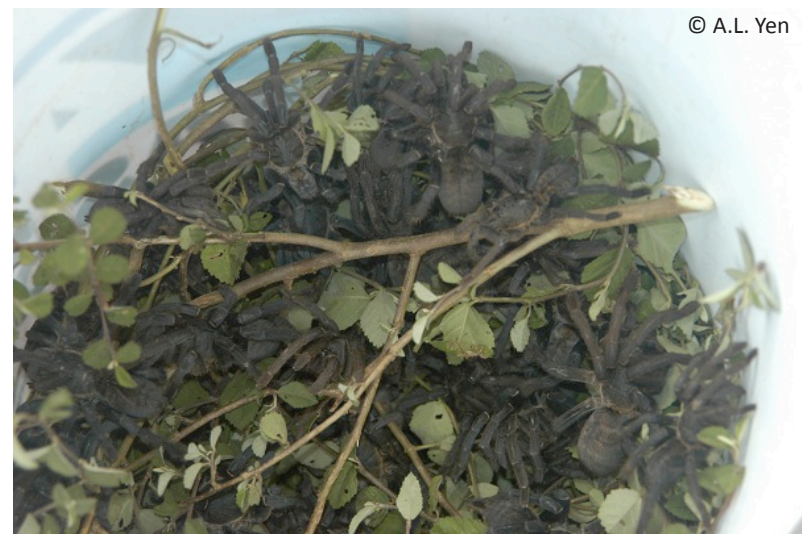

Image 3. Live tarantulas for sale at Skun

The customers are mainly visitors to Skun (local and international), and two vendors stated that a large customer group was Vietnamese who purchased live specimens to marinate in rice wine for medicinal purposes. The price quoted during this visit was 1,000 Riel (approximately US\$0.25) per spider. 
One vendor related that she purchases spiders from a wholesaler who collected them in the Sandan District of Kompong Thom Province. The wholesaler brings live spiders to Skun every 3-4 days. This vendor purchases 100 spiders at a time, and pays 400 Riel per spider and sells cooked ones for 1000 Riel. She sells 50-60 per day. However if we use these figures conservatively, and assuming that there are 30 vendors operating around Skun, and each sold 50 spiders per day, then this gives an estimate of 1500 spiders sold daily at Skun. This does not take account of spiders sold in Phnom Penh that may be purchased elsewhere. Even if the figure is lower, there is no doubt that a lot of spiders are sold every day, and there are crucial unanswered questions about both the sustainability of this trade and the potential ecological implications of overharvesting a large invertebrate predator on ecosystem function.

There are several fundamental questions that need to be addressed if this spider trade is to have a secure future:

(1) Identity of the spider: It is imperative that the scientific identity of the spiders sold be confirmed. While the locals call them a-ping, the only certainty that we have is that they are large ground-dwelling theraphosid spiders. Internet articles give two scientific names: Haplopelma longipes Von Wirth \& Striffler, 2005 and Haplopelma albostriatum (Simon, 1886). Platnick (2012) lists 11 species of Haplopelma from Borneo, Cambodia, China, Myanmar, Thailand, Malaysia, Singapore and Vietnam. The species of interest around Cambodia are H. albostriatum (Cambodia, Myanmar and Thailand), H. lividum Smith, 1996, H. longipes in Cambodia and Thailand, H. minax (Thorell, 1897) in Myanmar and possibly $H$. vonwirthi Schmidt, 2005 which is found in "Southeast Asia". It is possible that the spiders sold could be a mixture of different species, especially if spiders are being imported from more distant parts of Cambodia, and it could involve species in other genera. There may still be undescribed theraphosid spiders in the region. The identity needs to be resolved because any attempts to make the trade more sustainable will require accurate information on the biology and population dynamics of the species, so we need to do this on a known species rather than on a potential mixture of species.

(2) Biology and population dynamics: Sustainable spider harvesting will require information on their biology (life history, phenology), population dynamics (longevity, fecundity, age structure of populations), distribution, and habitat dependence. No information is available on these.

(3) The market chain: A better estimate of the extent of the trade is required. It is likely that the nature of the market chain is changing over time. The trade probably involves local collectors and vendors around Skun selling them locally. It has increased: importing spiders from other provinces, and an increased market that includes tourists. With better transport infrastructure, the turnover in spiders could increase and could place greater pressures on wild populations. A better understanding of the market chain would be assisted by better information on who actually purchases the spiders, why they purchase them (to eat, to pickle, or just out of curiosity), the ratio of cooked to live spiders sold, and how the trade fluctuates across the year (for example, is the trade slower during the wet season?). There is considerable divergence of opinion on the identity of the buyers: locals, Cambodian visitors (from other parts of Cambodia and from overseas), Vietnamese tourists are mentioned regularly by vendors, as well as other foreign tourists.

(4) Conservation status: Platnick (2006) identified 22 species of North and Central American tarantulas that are listed in CITES. They are threatened by habitat destruction and over collecting for the pet trade. At this stage, there is inadequate information on whether a-ping is of conservation concern because we do not have the information on its identity, population dynamics, and trade figures. While harvesting the spiders for sale is probably the main pressure on the populations, habitat destruction cannot be overlooked. The information from Skun is contradictory, with claims that spiders have declined because of conversion of forests to cash crops to claims that they are collected in cashew nut plantations.

(5) Sustainability: Theraphosid spiders are generally long-lived (Gallon undated) so determining the effects of harvesting on the population age structure and subsequent population dynamics is important. The fact that spider numbers around Skun have been substantially reduced suggests that the effects of overharvesting are severe. It would be important to assess spider populations around the forests of Skun to determine whether the reduced populations can recover in time if they have not already become extinct. A-ping is a large (for an invertebrate) ground-dwelling predator that apparently occurs in high density (judging by the numbers collected and sold), the ecological implications for ecosystem services in the forests if they are overcollected could be immense.

(6) Captive breeding potential: Due to the interest of keeping tarantulas as pets, there is a considerable amount of information available on captive breeding 
of many species, including Haplopelma albostriatum (Tansley 2006). There are dubious internet reports claiming that some of the a-ping are reared. While the knowledge on breeding and rearing of many tarantula species is available, it is generally used where small numbers are involved such as scientific research and the pet trade. The breeding of large numbers of longer-lived predators for commercial purposes presents many more technical challenges.

(7) Defanging: There are reports that the bites from many tarantula are painful but not lethal (Gallon undated). The spiders that are collected are "defanged" when they are collected. The reasons for this are uncertain, but it could be to prevent the spiders attacking each other (live spiders are stored together in buckets) and to prevent them biting people (holding live spiders at Skun is very common with both vendors and buyers). This raises an ethical issue in that it means after defanging, the spiders cannot feed.

(8) Real benefits or not? Search for alternatives: The reasons cited as to why spiders are eaten have already been outlined. It is important to determine whether the spiders do have real nutritional value or medicinal benefits. Research undertaken by the University of Copenhagen (Denmark) indicates that a-ping have levels of zinc that can assist overcoming child malnutrition issues if used as one of several additives to food (Nanna Roos pers. comm. January 2012). With such potential benefits, the matter of sustainability of supply is very important, and there will be a need to ensure sustainable production of spiders, either in the wild or in a semi-domestication context, or else seek alternative sources for these nutrition and medicinal compounds. Otherwise demand will result in decreased supply, an increase in prices, which ultimately will put a greater demand for supply.

(9) Alternative income sources for vendors: It has to be borne in mind that the spider trade is situated in a very poor country. The people who collect and sell a-ping rely on the income derived from the trade. It is imperative that the trade either be made sustainable or else alternative sources of income be found for these people.

There is no doubt that there are a lot of unanswered questions about the a-ping trade in Cambodia. It is an important part of the local economy and an important part of local Cambodian folklore (although possibly recent). However, if it is to have a long term future, the questions raised about identity of the species, its biology and population dynamics, the market chain, and whether they actually have benefits need to be addressed.

\section{REFERENCES}

Bristowe, W.S. (1932). Insects and other invertebrates for human consumption in Siam. Transactions of the entomological Society of London 80: 387-404.

Byrne, R. (2009). Cambodian spiders under threat. Khmer Media. <http://mediakh.net/business-and-eco/cambodian-spiders-underthreat $>$ [Accessed 17 February 2012].

CamboGuide (undated) Delicious (?) spiders. <http://www. camboguide.com/food-culinary/khmer-freaky-food/spiders> [Accessed 12 February 2012].

DuFord, D. (2009). How to eat fried tarantula in Cambodia. <http:// www.worldhum.com/features/how-to-eat-fried-tarantulas-incambodia-20091201> [accessed 07 February 2012].

Fuller-Love, H. (2011). Cambodia's surprising cuisine: Spiders, anyone? <http://articles.latimes.com/2011/nov/20/travel/la-trcambodiafood-20111120> [Accessed 02 February 2012].

Gallon, R.C. (undated). The natural history of Tarantula spiders. British Tarantula Society. <http://www.bts.ndirect.co.uk/natural.htm> [Accessed 1 March 2012].

Garcia, G. (2012). Wildlife population status in the world, illegal trading, and conservation actions. <http://www.tarantulasdemexico.com/ en/statuspoblacion_en.htm> [Accessed 01 February 2012].

Machkour-M'Rabet, S., Y. Hénaut, P. Winterton \& R. Rojo (2011). A case of zootherapy with the tarantula Brachypelma vagans Ausserer, 1875 in traditional medicine of the Chol Mayan ethnic group in Mexico. Journal of Ethnobiology and Ethnomedicine 7: 12.

Meyer-Rochow, V.B. \& S. Changkija (1997). Uses of insects as human food in Papua New Guinea, Australia, and North-East India: cross cultural considerations and cautious conclusions. Ecology of Food and Nutrition 36: 159-187.

Midena, K. (2010). Spider hunting the latest craze in Cambodia. <http:// www.news.com.au/travel/news/spider-hunting-the-latest-craze/ story-e6frfq80-1225880970301> [Accessed 09 February 2012].

Paoletti, M.G. \& D.L. Dufour (2005). Edible Invertebrates among Amazonian Indians: A critical review of disappearing knowledge, pp. 293-342. In: Paoletti, M.G. (ed.). Ecological Implications of Minilivestock. Science Publishers, Inc., Enfield, New Hampshire.

Phnom Penh Post (2012). The mystery of the missing spider sanctuary. <http://www.phnompenhpost.com/index.php/2012012754200/ Lifestyle/the-mystery-of-the-missing-spider-sanctuary.html> [Accessed 07 February 2012].

Platnick, N. (2006). Taxonomic checklist of CITES listed spider species. Information extracted from Platnick, N. (2006) The World Spider Catalog V. 6.5 (as of 07 April 2006). The American Museum of Natural History.

Platnick, N. (2012). The World Spider Catalog, Version 12.5. The American Museum of Natural History. <http://research.amnh.org/ iz/spiders/catalog/> [Accessed 01 February 2012].

Read, B.E. (1941). Chinese Materia Medica Insect Drugs. Peking Natural History Bulletin, Peking.

Rigby, R. (2002). Cambodia: eating tarantulas with the spiderwomen of Skuon. <http://www.rhymer.net/tdarchive28b.htm> [Accessed 29 May 2011].

Robinson, M.H. \& B. Robinson (1976). The ecology and behavior of Nephila maculata: A supplement. Smithsonian Contributions to Zoology 218: 1-22.

Serath (2011). Fried tarantula, a popular delicacy in Cambodia. <http:// khmerization.blogspot.com/2011/11/fried-tarantula-populardelicacy-in.html> [Accessed 16 December 2011].

Tansley, G. (2006). Breeding Haplopelma albostriatum. Journal of the British Tarantula Society 21: 108-112.

von Wirth, V. \& B.F. Striffler (2005). Neue Erkenntnisse zur Vogelspinnen - Unterfamilie Ornithoctoninae, mit Beschreibung von Ornithoctonus aureotibialis sp. $\mathrm{n}$. und Haplopelma longipes sp. $\mathrm{n}$. (Araneae, Theraphosidae). Arthropoda 13: 2-27.

Wijesinghe, P. (undated). Fried spiders. <http://www.articlesnatch. com/Article/Fried-Spider---The-CambodianDelicacy/2485307> [Accessed 17 February 2012]. 